\title{
Health Care Seeking and Risk Behaviors among High School Students in the Context of a School-Based Health Center
}

Hilda Audardottir-Goulay, MS4,${ }^{1}$ Beka Mullen, MS4, ${ }^{1}$ Allen Greiner, M.D. ${ }^{1,2}$

Kenosha Hobson, M.D., ${ }^{1,3}$ Catherine L. Satterwhite, Ph.D., M.S.P.H., M.P.H. ${ }^{1,4}$

${ }^{1}$ University of Kansas School of Medicine-Kansas City

${ }^{2}$ Department of Family Medicine

${ }^{3}$ Department of Pediatrics

${ }^{4}$ Department of Preventive Medicine and Public Health

\begin{abstract}
Background. To address adolescent health needs in urban Wyandotte County, Kansas, a schoolbased health center (SBHC) was opened in March 2012. Students were surveyed to inform SBHC operations.

Methods. All Wyandotte High School students were invited to complete an online survey in class in May 2012. Questions on demographics, health care seeking behaviors, behavioral risk factors, and missed school days were included.

Results. Of 1,240 eligible students, 398 responded (32.3\%). Nearly half (45.8\%) reported that the emergency room or hospital was the location where they usually would seek health care. Females were more likely than males to report less access to mental health counseling (15.1\% vs $10.8 \%, \mathrm{p}=0.01)$ or reproductive health care $(7.7 \%$ vs $5.7 \%, \mathrm{p}=0.03)$ when needed and were more likely to miss school due to a health problem $(54.0 \%$ vs $37.9 \%$ missed $\geq 1$ day in past 4 weeks, $\mathrm{p}=0.006)$. Males were more likely to report having had sex $(59.2 \%$ vs $46.9 \%, \mathrm{p}=0.02)$ while females were more likely to report never using a condom when having sex $(30.6 \%$ vs $18.3 \%, \mathrm{p}=0.001)$. Almost two-thirds $(61.9 \%)$ of respondents were aware of the SBHC; $18.7 \%$ had used the SBHC.
\end{abstract}

Conclusions. Students do not have adequate access to primary care, including sexual and mental health care. Using these data, the SBHC can be better adapted to meet student needs.

KS J Med 2013; 6(4):124-132.

\section{Introduction}

School-based health centers (SBHCs) are on-site health care facilities aimed at addressing the preventive, acute, and chronic health needs of students. ${ }^{1}$ These centers are often a collaboration between schools and other community partners, including local/state health departments, hospitals, medical schools, and other community-based organizations. SBHCs are a rapidly-growing model of adolescent health care delivery in communities with historically inadequate access to care. In 1988, 120 SBHCs existed; by 2008, that number had climbed to over $1,900 .^{2}$ SBHCs are positioned to facilitate the coordination of comprehensive care for adolescents and meet the mental health and medical needs unique to this population. ${ }^{3}$

Over half of SBHCs are in urban settings. The National Assembly on SchoolBased Health Care (NASBHC) reported that students in schools with SBHCs are "predominantly members of minority and ethnic populations who have historically experienced under-insurance, uninsurance, or other healthcare access disparities". Based on data from the 2007-2008 school year, $36.8 \%$ of the students served by SBHCs were Hispanic or Latino, $29.5 \%$ were white, and $26.2 \%$ were black. This 
distribution also describes the demographics of adolescents in Wyandotte County, Kansas. ${ }^{4}$

In 2012, Wyandotte County was 97 out of the 100 ranked counties in the state of Kansas by the Kansas Health Institute, based on health outcomes (morbidity and mortality) as well as health factors (health behaviors, clinical care, socioeconomic factors, and physical environment). ${ }^{5}$ Wyandotte County's population is predominantly urban, ${ }^{4}$ with over $20 \%$ of households falling below the poverty line, compared to $12 \%$ for Kansas as a whole. Wyandotte County is undergoing drastic demographic changes as well. Between 1990 and 2011, the Hispanic population of Wyandotte County increased from under $7 \%$ to just over $26 \%{ }^{4}$.

The adolescent population magnifies the differences between Wyandotte County and the rest of the state. Over $75 \%$ of children qualify for free and reduced lunches and $31 \%$ live below the poverty line, and $37 \%$ of Wyandotte County youth are Hispanic. ${ }^{4}$ Adolescents in Wyandotte County have other risk factors contributing to adverse health outcomes; in 2011, Wyandotte County represented over $10 \%$ of all reported chlamydia cases in Kansas, ${ }^{6}$ despite including only about $5 \%$ of the state's population.

In March 2012, a community partnership consisting of USD 500 (Kansas City, KS public schools), the University of Kansas (KU) School of Medicine, A Better KCK, Communities Creating Opportunities (CCO), and administrators and teachers at Wyandotte High School (WHS) was formed. The goal of this partnership was to address health issues in the adolescent population in the urban core of Kansas City, KS. The partnership conducted a needs assessment that showed far-reaching deficits in the accessibility, quality, and scope of the care that adolescents receive in Wyandotte
County (unpublished data). Based on this needs assessment, a school-based health center, named BullDoc by the student body, was implemented and opened in the spring semester of 2012 at WHS. To evaluate the BullDoc pilot and capture data to inform any changes in clinic operation, a cross-sectional survey of students enrolled in WHS was conducted to document health-related behavior and health care access issues.

\section{Methods}

Participants. Wyandotte High School is one of four high schools in USD 500, the school district serving urban Kansas City, KS. BullDoc, the onsite SBHC at WHS, operates every Wednesday morning during the academic school year from 9:00 am to $12: 30 \mathrm{pm}$ and is staffed by volunteer $\mathrm{KU}$ medical students and family physicians. Students can access BullDoc through appointments or as walk-ins, as long as adequate parental consent (a completed clinic registration form) is on file. All students enrolled at WHS are eligible to attend the SBHC and were invited to participate in a survey assessing healthrelated issues in May 2012.

Instruments. WHS students were invited to complete an online survey assessing health care seeking behavior, basic health and nutrition practices, health-related reasons for missing school days, risk behaviors, and BullDoc awareness and utilization. The survey was based upon an existing, validated survey used to conduct the California Healthy Kids Survey in September 2011. ${ }^{7}$

To assess healthcare access and utilization, students were asked how often they seek medical attention, where they go for their medical care, when the last time they saw a doctor or dentist was, and whether or not specific types of health care (including counseling) were available when the student needed it. Students also were 
asked how many days they missed school in the last four weeks due to health-related concerns: illness, stress, depression, family problems, alcohol use, and drug use. Questions included an assessment of health behaviors such as sexual activity, alcohol, tobacco, and drug use, and diet. Finally, students answered questions concerning BullDoc awareness, use, and desired clinic services. Demographics included sex, grade level, race, and ethnicity.

Procedure. The 32-question survey was anonymous and voluntary and was introduced by teachers in the classroom on May 1, 2012. Two weeks after the initial survey launch, on May 14, 2012, teachers were asked to provide one additional reminder to students to encourage them to complete the survey. Students, each of whom had their own laptop computer, were given the opportunity to complete the survey during their homeroom class. The survey was administered in May 2012, two months after the BullDoc SBHC was opened, and remained open for two weeks.

Data analysis. Data analysis was conducted using SAS (Version 9.3, Cary, NC). Response frequencies were summarized, and differences in proportions between sexes were accessed using a Chisquare test.

\section{Results}

Approximately 1,240 students were eligible and invited to complete the survey. Of these, 399 students responded to the survey (32.2\%). Most surveys were completed fully and most questions were answered by at least $99 \%$ of respondents. A comparison of student respondent demographics and the total population of Wyandotte High School is shown in Table 1.

Table 1. Demographic characteristics of survey respondents, Wyandotte High School, 2012.

\begin{tabular}{|l|c|c|c|}
\hline Characteristic & $\begin{array}{c}\text { Number of Survey } \\
\text { Responders (n, \%) }\end{array}$ & p-value & $\begin{array}{c}\text { Proportion of WHS } \\
\text { student body* }\end{array}$ \\
\hline Sex & $159(42.6)$ & 0.004 & $50.0 \%$ \\
Male & $214(57.4)$ & & $50.0 \%$ \\
Female & $132(35.2)$ & $<0.001$ & $37.4 \%$ \\
Grade Level & $89(23.7)$ & & $26.3 \%$ \\
Freshman & $122(32.5)$ & & $20.3 \%$ \\
Sophomore & $32(8.5)$ & 0.213 & $16.0 \%$ \\
Junior & $198(53.2)$ & & $52.0 \%$ \\
Senior & $174(46.8)$ & $<0.001$ & $48.0 \%$ \\
Ethnicity & $98(48.8)$ & & N/A \\
Not Hispanic & $33(16.4)$ & & \\
Hispanic & $38(18.9)$ & & \\
Race & $5(2.5)$ & & \\
Black & $27(13.4)$ & & \\
White & & \\
Asian & & \\
Other & & \\
Multi-race & & & \\
\hline
\end{tabular}

$\mathrm{N} / \mathrm{A}=$ not available

*Based on published 2011 enrollment data. 


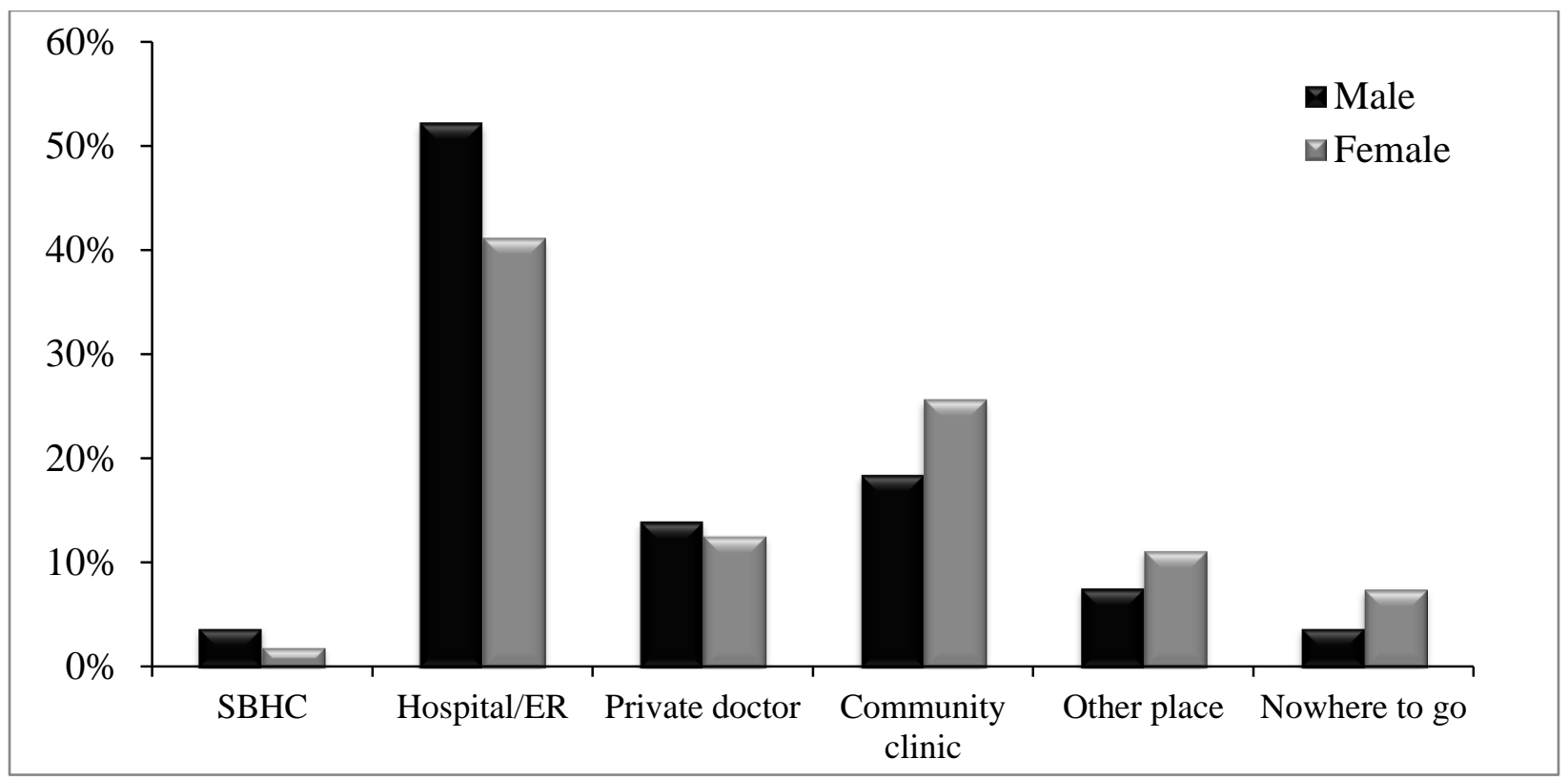

Figure 1. Usual location where students seek health care, Wyandotte High School, 2012.

Access to health care. Nearly half $(45.8 \%)$ of respondents reported that the emergency room or hospital was the location where they would usually seek health care (Figure 1). The next most frequently reported venue for seeking health care was a community clinic $(22.6 \%)$, followed by a private doctor $(13.2 \%)$. While the vast majority of respondents reported having somewhere to access health care services, $5.9 \%$ reported having nowhere to go.

Overall, the distribution of health care seeking locations was similar between males and females $(\mathrm{p}=0.10)$. Almost two-thirds $(66.5 \%)$ of respondents reported that they had seen a doctor or nurse within the last year; $19.6 \%$ did not know the last time they had seen a doctor for any reason (Table 2). When asked about the last time they had seen a dentist, $53.2 \%$ of respondents reported a visit in the last year; $8.9 \%$ reported never having seen a dentist. Female respondents were more likely than males to report that mental health counseling was rarely available when they needed it $(15.1 \%$ vs. $10.8 \%$, respectively, $\mathrm{p}=0.01$ ). This was likewise true for reproductive health services.

School absence. Over half of all female respondents reported that they had missed at least one day of school in the past four weeks due to a health problem (e.g., cold/flu, illness, injury, toothache, stomachache, asthma) compared to $37.9 \%$ of male respondents $(p=0.006$; Figure 2$)$.

When asked how many days they missed due to stress, $75.1 \%$ responded that they had missed no days, $14.1 \%$ reported missing one to three days, and $5.4 \%$ reported missing four or more days. A similar distribution of missed school days due to feeling sad/depression and family problems was seen. Few respondents reported missing school due to alcohol or drug use.

Nutrition and food security. On the day the survey was completed, half of respondents reported that they had eaten breakfast that morning and half did not (Table 3). Over a quarter of respondents (28.4\%) reported that they had at some time cut their meal size or skipped meals because there was not enough money for food. 
Table 2. Health care seeking behaviors and SBHC awareness among Wyandotte High School students, 2012.

\begin{tabular}{|c|c|c|c|c|}
\hline & \multicolumn{4}{|c|}{ Number of Survey Responders $(\mathrm{n}, \%)$} \\
\hline & Males & Females & Total & p-value \\
\hline Last time saw doctor for any reason & & & & 0.38 \\
\hline$<1$ year & $103(64.8)$ & $145(67.8)$ & $248(66.5)$ & \\
\hline $1-2$ years & $16(10.1)$ & $26(12.2)$ & $42(11.3)$ & \\
\hline$>2$ years & $3(1.9)$ & $7(3.3)$ & $10(2.7)$ & \\
\hline Don't know & $37(23.3)$ & $36(16.8)$ & $73(19.6)$ & \\
\hline Last time saw doctor for check-up & & & & 0.31 \\
\hline Never & $8(5.0)$ & $13(6.1)$ & $21(5.6)$ & \\
\hline$<1$ year & $90(56.6)$ & $131(61.2)$ & $221(59.3)$ & \\
\hline $1-2$ years & $28(17.6)$ & $24(11.2)$ & $52(13.9)$ & \\
\hline$>2$ years & $6(3.8)$ & $14(6.5)$ & $20(5.4)$ & \\
\hline Don't know & $27(17.0)$ & $32(15.0)$ & $59(15.8)$ & \\
\hline Last time saw dentist & & & & 0.79 \\
\hline Never & $14(8.9)$ & $20(9.4)$ & $34(9.2)$ & \\
\hline$<1$ year & $79(50.0)$ & $118(55.7)$ & $197(53.2)$ & \\
\hline 1-2 years & $30(19.0)$ & $34(16.0)$ & $64(17.3)$ & \\
\hline$>2$ years & $13(8.2)$ & $13(6.1)$ & $26(7.0)$ & \\
\hline Don't know & $22(13.9)$ & $27(12.7)$ & $49(13.2)$ & \\
\hline Care rarely available when needed & & & & \\
\hline Medical care & $30(18.9)$ & $36(17.0)$ & $66(17.8)$ & 0.18 \\
\hline Mental health counseling & $17(10.8)$ & $32(15.1)$ & $49(13.2)$ & 0.01 \\
\hline Reproductive health & $9(5.7)$ & $16(7.7)$ & $25(6.8)$ & 0.03 \\
\hline Help with diet/exercise & $20(12.6)$ & $31(14.8)$ & $51(13.8)$ & 0.24 \\
\hline Dental care & $23(14.6)$ & $26(12.3)$ & $49(13.3)$ & 0.14 \\
\hline Aware of SBHC (BullDoc) existence & $96(61.9)$ & $132(62.3)$ & $228(62.1)$ & 0.95 \\
\hline
\end{tabular}

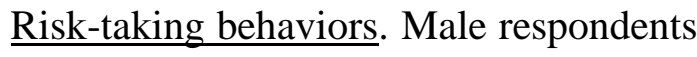
were more likely to report ever having been sexually active than female students $(59.2 \%$ vs $46.9 \%$, respectively, $\mathrm{p}=0.02$; Table 3 ). Among those who had sex, only $28.6 \%$ of females reported always using a condom when they have sex, compared to $53.8 \%$ among males $(\mathrm{p}=0.001) ; 30.6 \%$ of female respondents reported that they never used condoms during sex. Similarly, $43.9 \%$ of females reported using no contraceptive method the last time they had sex. Only $21.5 \%$ of males and $13.3 \%$ of females reported dual contraceptive methods, condoms and birth control, at the last sex event. Among sexually active females,
$62.2 \%$ (61 of 98 respondents) reported that they had taken a pregnancy test at some point; $17.4 \%$ (17 of 98 respondents) reported having ever been pregnant. About two-thirds of respondents $(65.8 \%)$ reported that they had never smoked cigarettes. Only $4.3 \%$ of respondents reported being regular smokers currently. When respondents were asked if they had any interest in changing any of their behaviors (e.g., behaviors related to sex, drugs, or drinking), $13.9 \%$ of students said yes. Many open-ended responses concerned a desire to change behaviors related to drugs or alcohol, despite a low proportion of respondents reporting use. 


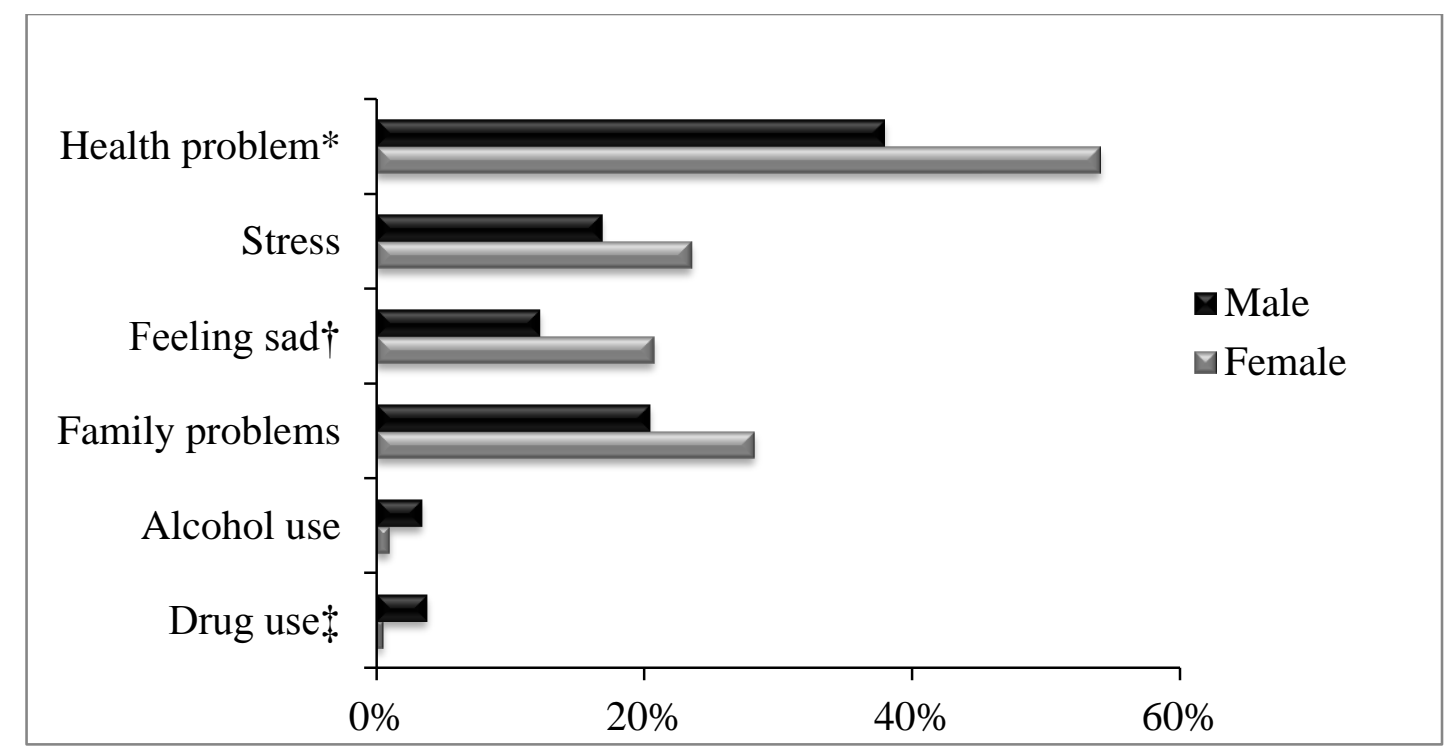

$* \mathrm{p}=0.006 ; \dagger$ Or depression; + Other than alcohol

Figure 2. School absences (> 1 day) due to health-related issues or concerns among Wyandotte High School students, 2012.

Table 3. Health risk behaviors among Wyandotte High School students, 2012.

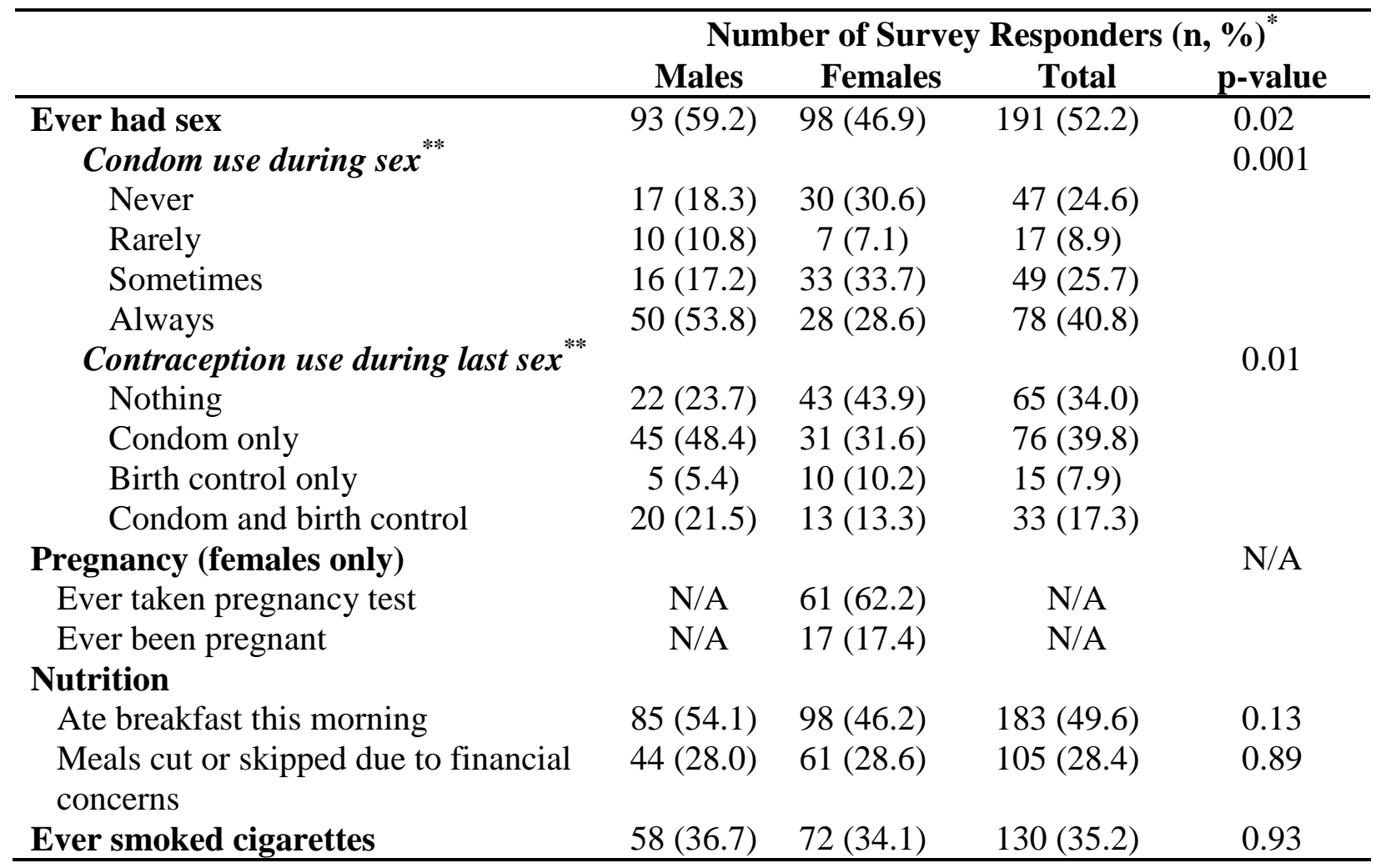

* Totals were calculated from the overall number of subjects with available data (e.g., 366 men and women had sexual history data; 191 (52.2\%) reported having ever had sex.

** Respondents reporting having had sex at least once (93 males, 98 females, 191 total). 
Awareness and usage of BullDoc. At the time of survey administration, BullDoc had been operational only for about two months. Despite the short time frame, $61.9 \%$ of respondents stated that they were aware of BullDoc, the school-based health center at their high school. About one-fifth (18.7\%) of student respondents stated that they had used the clinic for information or services; $23.1 \%$ stated they planned to use the clinic in the next six months, while $48.6 \%$ were not sure. Respondents generally reported positive associations with the presence of BullDoc (data not shown). Females (74.5\%) and males (65.8\%) agreed or strongly agreed with the statement "I like having it at my school" $(\mathrm{p}=0.02)$.

\section{Discussion}

Students attending Wyandotte High School, an urban Kansas City school, reported sub-optimal access to care and several risk factors with the potential to impact their health. Almost half of the respondents reported that a tertiary care facility (emergency room or hospital) was their primary source of healthcare. Furthermore, females reported rarely receiving care they needed in areas such as reproduction and mental health.

After two short months of operation, a majority of respondents were aware of the BullDoc clinic at WHS. Almost one-third of respondents reported that they would like more information on BullDoc. Student reviews from other SBHCs illustrated that the health center in their schools filled a void where teenagers find it difficult to access medical care, that they trusted those who worked at the health center, and that their care left a lasting impression of prioritizing their health in the future. ${ }^{8}$ Students at schools with SBHCs have greater improvement in their Health-Related Quality of Life (HRQOL) scores compared to students who do not.
While survey participation was satisfactory, results may not represent the whole WHS student body and may not be generalizable to adolescents attending urban public high schools. However, nearly onethird of the school population responded to the survey in its entirety. Responses to some questions emphasized that the survey seemed to represent issues impacting students. For example, over $90 \%$ of WHS students qualify for free and reduced lunches, which could suggest that a significant portion of the school population suffers from food insecurity, although direct data are not available. About half of survey respondents reported that they did not eat breakfast and over a quarter reported missing a meal due to lack of food or money.

Respondents clearly noted a need for mental health care. The survey data, however, did not provide them an opportunity to describe issues in their lives that would lead to that need. It is important for clinicians to differentiate among needs for academic counseling, diet and exercise education, sexual health counseling, and drug and alcohol use counseling. To maintain a short survey length, however, only a small group of questions was asked. Nonetheless, even a short survey resulted in valuable insights into the health needs of WHS students. Students answered questions individually and anonymously, providing a unique insight into adolescent views on their own health.

\section{Implications for School Health}

WHS students demonstrated a clear lack of access to primary care and increased use of tertiary facilities like the emergency room, in contrast to a 2011 national CDCsponsored health survey in which $74.9 \%$ of youths aged 12-17 responded that they had a doctor's office as a regular source of healthcare, $22.8 \%$ responded that they used 
a clinic, and only $0.9 \%$ used an emergency room. ${ }^{10}$ Recent research has described specific benefits of SBHCs for students. In schools with SBHCs, children with asthma are found to have fewer visits to the emergency department, fewer hospitalizations, and better school attendance. ${ }^{11}$ SBHC users are also more likely to have more primary care physician visits than visits at other sites when compared to their counterparts who had never used an SBHC. Likewise, students attending an SBHC are more likely to have had an influenza vaccine, a tetanus booster, and a hepatitis $B$ vaccination. $^{12}$

SBHC availability has been associated with decreases in missed school days. ${ }^{13}$ Half of female and $40 \%$ of male WHS respondents reported missing at least one day of school in the past four weeks due to a health- or family-related reasons, a concern that might be improved by an ongoing SBHC presence. The availability and use of mental health services also has been linked with a statistically significant increase in grade point average. ${ }^{14}$ With such information, efforts can be made to advocate for additional resources to continue to serve an underserved adolescent population.

Another specific area of need identified through the survey and common throughout adolescence is sexual health. Many students reported being sexually active, but relatively few reported using adequate contraception

\section{References}

${ }^{1}$ National Assembly on School-Based Health Care. School-Based Health Centers: A National Definition. June 20, 2002. Available at: http://ww2.nasbhc. org/RoadMap/PUBLIC/Advocacy_SBHC definition.pdf. Accessed October 1, 2013.

2 Strozer J, Juszczak L, Ammerman A. School-Based Health Centers. National Census School Year 2007-2008. Available at: http://ww2.nasbhc.org/NASBHC or barrier protection to prevent pregnancy and sexually transmitted infections. The high proportion of sexually active females reporting no barrier or hormonal contraception, along with many females reporting having taken a pregnancy test suggested that programs targeted toward adolescent females would be of great importance, addressing a clear need for sexual health education.

Survey findings clearly show that adolescents at WHS, and likely in many urban high schools in Kansas City and across the county, need more access to primary, preventive health care, with an emphasis on sexual and mental health. All of these findings support the goal of school health. BullDoc should continue to address these areas and make efforts to improve and expand the availability of services.

\section{Acknowledgement}

This survey was conducted under the authority of the Principal of Wyandotte High School as an internal quality-improvement measure with agreement from USD 500 (Kansas City, KS, public schools), faculty in Family Medicine and Preventive Medicine at the University of Kansas (KU) School of Medicine, A Better $K C K$, Communities Creating Opportunities (CCO), and administrators and teachers at Wyandotte High School.

CensusReport07-08.pdf. Accessed October 1, 2013.

3 Pastore DR, Murray PJ, Juszczak L, Society for Adolescent Medicine. Schoolbased health center: Position paper of the Society for Adolescent Medicine. J Adolesc Health 2001; 29(6):448-450. PMID: 11728894.

${ }^{4}$ US Census Bureau. Wyandotte County, Kansas. 2012. Available at: http://quick 
facts.census.gov/qfd/states/20/20209.html. Accessed October 1, 2013.

${ }^{5}$ University of Wisconsin Population Health Institute. County Health Rankings and Roadmaps. 2012 Rankings. Available at: http://www.countyhealthrankings.org/si tes/default/files/states/CHR2012_WI.pdf.

Accessed October 1, 2013.

${ }^{6}$ Kansas Department of Health and Environment. Reported Cases of Chlamydia by County. Sexually Transmitted Disease Program 2011. Available at: http://www.kdheks.gov/std/ download/std_reports/CY2011_Stat_Pack Data.pdf. Accessed October 1, 2013.

7 Philip R. Lee Institute for Health Policy Studies, University of California, San Francisco. California Healthy Kids Survey Section G-1: Health Care (Existing SBHC Sites) 2011/2012. 2011. Available at: http://www.berkeleyschools.net/wp-conten t/uploads/2012/01/CHKS_UCSF_Module _ G_High_School.pdf. Accessed October 1, 2013.

${ }^{8}$ Sanchez S, Rodriguez M, Arnold D. The Bellevue/Norman Thomas High School based health center: Student perspectives. Curr Probl Pediatr Adolesc Health Care 2012; 42(6):161. PMID: 22677516.

9 Wade TJ, Mansour ME, Line K, Huentelman T, Keller KN. Improvements in health-related quality of life among school-based health center users in elementary and middle school. Ambul Pediatr 2008; 8(4):241-249. PMID: 18644546.
${ }^{10}$ Bloom B, Cohen RA, Freeman G. Summary health statistics for U.S. children: National Health Interview Survey, 2011. National Center for Health Statistics. Vital Health Stat 10(254). 2012. Available at: http://www.cdc.gov/nchs/ data/series/sr_10/sr10_254.pdf. Accessed October 1, 2013.

${ }^{11}$ Clayton S, Chin T, Blackburn S, Echeverria C. Different setting, different care: Integrating prevention and clinical care in school-based health centers. Am J Public Health 2010; 100(9):1592-1596. PMID: 20634447.

${ }^{12}$ Allison MA, Crane LA, Beaty BL, Davidson AJ, Melinkovich P, Kempe A. School-based health centers: Improving access and quality of care for low-income adolescents. Pediatrics 2007; 120(4):e887894. PMID: 17846146.

${ }^{13}$ Centers for Disease Control and Prevention. Sexual Risk Behavior: HIV, STD, and Teen Pregnancy Prevention. August 26, 2013. Available at: http://www.cdc.gov/ HealthyYouth/sexual behaviors/. Accessed October 1, 2013.

${ }^{14}$ Walker SC, Kerns SE, Lyon AR, Bruns EJ, Cosgrove TJ. Impact of school-based health center use on academic outcomes. J Adolesc Health 2010; 46(3):251-257. PMID: 20159502.

Keywords: school health services, reproductive health, sexually transmitted diseases, health services accessibility, healthcare quality, access, and evaluation 